\title{
Prevalence of self-reported Type 2 diabetes mellitus and associated socio-economic- demographic factors among adults above 20 years in a residential area of Delhi
}

\author{
Reeta Devi', Bimla Kapoor², M. Meghachandra Singh ${ }^{3}$ \\ ${ }^{1}$ Assistant Professor, School of Health Sciences, Indira Gandhi National Open University, New Delhi, ${ }^{2}$ Dean, IL \& \\ FS Skills Health Academy, Former Director and Professor, School of Health Sciences, Indira Gandhi National Open \\ University, New Delhi, ${ }^{3}$ Professor, Department of Community Medicine, Maulana Azad Medical College, New Delhi
}

\section{A B S T R A C T}

Background: There is changing epidemiology of type 2 diabetes mellitus in India. Few studies have reported prevalence of self reported diabetes in Delhi. Aims and Objectives: To assess the prevalence of self-reported Type 2 diabetes mellitus (T2DM) and find out its association with socio-economic-demographic factors among adults above 20 years in a residential area of Delhi. Materials and Methods: This was a community based crosssectional study done in a residential area of East Delhi. The subjects were identified by door to door survey based on available records and self-report. They were interviewed using a pre-tested interview schedule with items on socio-economic and demographic characteristics. Chi-square test was used for qualitative data. Multivariate logistic regression analysis was used to find out associated factors with T2DM. Odds ratio $(95 \% \mathrm{CI})$ was calculated. ' $p$ ' $<0.05$ was considered significant. Results: The self-reported prevalence of T2DM was $8.5 \%(461 / 5444)$ among 20 years and above population. It was more in males $(9.1 \%)$ than females $(7.8 \%)$, highest $(25 \%)$ in primary educated, least $(7.3 \%)$ in graduates and above $(p<0.001)$. Age-specific prevalence was maximum $(22.4 \%$ in $60-69$ years), least $10.2 \%)$ in $20-29$ years $(p<0.001)$. Occupation wise, maximum $(19.2 \%)$ was in retired and least $(0.7 \%)$ in unemployed $(p<0.001)$. The associated factors were: age 50 years and above (OR 6.99, 95\% Cl 5.4-8.9), males (OR 1.33, 95\% Cl 1.07-1.65), secondary education (OR $1.39,95 \% \mathrm{Cl} 1.05-1.84$ ), unemployed (OR 1.45, 95\% Cl 1.15-1.83), per capita per month income Indian Rupees (INR) 20001 and above (OR 1.39, 95\% Cl 1.10-1.75). Conclusion: Self-reported prevalence of T2DM was $8.5 \%$, more among males, $>50$ years, retired, secondary educated and with per capita income per month of Rs 20001 and above. It is necessary to create awareness among the people to identify, manage and prevent T2DM.

Access this article online

Website:

http://nepjol.info/index.php/AJMS

DOI: 10.3126/ajms.v7i4.14616

E-ISSN: 2091-0576

P-ISSN: 2467-9100

Key words: Prevalence, Diabetes, Delhi

\section{INTRODUCTION}

Diabetes is characterized by high blood glucose levels due to defect in secretion of insulin, its action or both. Diabetes affects several organs such as eyes, kidneys, nerves, blood vessels, and heart results in their dysfunction, damage, or failure. ${ }^{1}$ Diabetes is emerging as a major non-communicable health problem globally with evidence of an epidemic in several low and middle income countries. It is reported to be the fourth or fifth leading cause of mortality in several high-income countries. $^{2}$

According to International Diabetes Federation (IDF) Atlas of 2014, it has been estimated that worldwide, 387 million people suffer from diabetes and it is expected 
to increase in number to 592 million by 2035. A large number of people with diabetes $(77 \%)$ are from low and middle-income countries. Globally, the number of undiagnosed cases of diabetes is expected to be 179 million and the most affected age-group is 40 to 59 years. It is estimated that one patient of diabetes died in every seven seconds in 2014 and there were 4.9 million deaths due to diabetes. ${ }^{3}$ As per estimates, India had 32 million diabetic subjects in 2000 , and it is projected to 80 million by $2030 .{ }^{4}$

The Indian Council of Medical Research (ICMR) conducted the first multicentric study in India during 1972-1975. The criterion of diabetes used was capillary blood glucose level more than $170 \mathrm{mg} / \mathrm{dl}$. The results showed that $3.0 \%$ and $1.3 \%$ were the prevalence of diabetes in urban and rural areas respectively. ${ }^{5}$

Studies done during the 1980s showed a higher prevalence of diabetes in urban areas i.e. $5 \%$ in Kudremukh, Karnataka (Ramachandran A et al) and 3.1\% in affluent families of Daryaganj, Delhi (Varma NPS et al) ${ }^{6,7}$ There was a rapid increase in the prevalence of diabetes type 2 in India from studies conducted during 1990s and 2000s. In Chennai, Ramachandran A et al reported the prevalence of type 2 diabetes rose to $11.6 \%$ in the same urban area, which had a prevalence of $8.2 \%$ five years earlier ${ }^{8,9}$ (Table 1). Other studies from different parts of India during 1990s, till early 2000s, showed wide variations in the prevalence of diabetes in the population ranging from $6.3 \%$ in Kashmir Valley (Zargar et al) in 2000 to $16.3 \%$ in Trivandrum (Raman et al) in 1999. ${ }^{10,11}$ The prevalence of 'known' diabetes was $1.9 \%$, and that of 'undiagnosed' diabetes was $4.3 \%$ in the Kashmir valley study. ${ }^{9}$ Some of the prevalence studies done during 1990s to 2015 are shown in Table 1.

\begin{tabular}{|c|c|c|c|}
\hline Authors & $\begin{array}{c}\text { Year of } \\
\text { publication }\end{array}$ & Place & $\begin{array}{l}\text { Prevalence } \\
\text { (\%) }\end{array}$ \\
\hline $\begin{array}{l}\text { Ramachandran A } \\
\text { et al. }{ }^{8}\end{array}$ & 1992 & Chennai & 8.2 \\
\hline $\begin{array}{l}\text { Ramachandran A } \\
\text { et al. }{ }^{9}\end{array}$ & 1997 & Chennai & 11.6 \\
\hline Shah SK et al. ${ }^{12}$ & 1999 & Guwahati & 8.2 \\
\hline Raman KV et al. ${ }^{11}$ & 1999 & Trivandrum & 16.3 \\
\hline Zargar AH et al. ${ }^{10}$ & 2000 & Kashmir Valley & 6.3 \\
\hline lyer SR et al. ${ }^{13}$ & 2001 & Mumbai & 7.5 \\
\hline Misra A et al. ${ }^{14}$ & 2001 & Delhi slum & 11.2 \\
\hline Mohan V et al. ${ }^{15}$ & 2003 & Chennai & 12.0 \\
\hline Gupta $\mathrm{R}^{16}$ & 2004 & Jaipur & 16.8 \\
\hline Mohan $\mathrm{V}^{17}$ & 2005 & Chennai & 15.5 \\
\hline Prabhakaran $\mathrm{D}^{18}$ & 2005 & Delhi & 15.0 \\
\hline Reddy KS ${ }^{19}$ & 2006 & National & 10.1 \\
\hline Ravikumar $\mathrm{P}^{20}$ & 2011 & Chandigarh & 11.1 \\
\hline Mustafa N21 & 2012 & Jabalpur & $11-18$ (range) \\
\hline Gujral UP22 & 2015 & Chennai & 38.0 \\
\hline
\end{tabular}

In order to obtain continuous surveillance of Non Communicable Diseases (NCD) risk factors in India, the World Health Organization (WHO) and the ICMR took up NCD Risk Factor Surveillance in five states of India in 2005. It represented different geographical locations (north, south, east and west/central India). The study included about 40,000 individuals aged 15 to 64 years with equal representation from urban, peri-urban (slum) and rural areas. The overall prevalence of self-reported diabetes study was 4.5 per cent. Urban area showed the highest prevalence $(7.3 \%)$, followed by peri-urban/slum $(3.2 \%)$ and rural areas $(3.1 \%){ }^{23}$

There is a significant change in the epidemiology of diabetes over the past few years in India. Such changes can be known from more recent epidemiological studies. Since there is increase in the non-communicable and lifestyle diseases, there is a need to study the changes in the prevalence of diabetes in urban areas of India. Moreover, estimates of the prevalence would help in providing recent data for diabetes type 2 . Few studies have been done in Delhi to estimate the prevalence of known diabetics in the general population. The present study was aimed to assess the prevalence of self-reported Type 2 diabetes mellitus (T2DM) and find out its association with socio-economic-demographic factors among adults above 20 years in a residential area of Delhi.

\section{MATERIALS AND METHODS}

This was a community based cross-sectional observational study conducted during October to December 13. The present study was conducted in Dilshad Garden, East Delhi due to familiarity and ease of access to the researchers. The residential buildings were built and developed by Delhi Development Authority (DDA). There were 21 blocks in the area named as per English alphabets. The large blocks were pockets ' $I$ ', 'J \& K' and these blocks were selected for the present study. For the purpose of the present study, target population refers to all persons aged 20 to 80 years residing in the study areas. The total population in the study areas was 6654 (1397 in 'I' and 5257 in 'J and K' pockets) residing in 2030 flats. The target population (20 years upto 80 years) was 5444 (81.8\%) (1150 in 'I' and 4294 in 'J and K' pockets).

\section{Sample size calculation}

The following information and formula was used to find out the prevalence of T2DM subjects.Anticipated population proportion of $\mathrm{T} 2 \mathrm{DM}=\mathrm{P}(7 \%$, based on the WHO and the ICMR NCD Risk Factor Surveillance, selfreported Diabetes in urban areas of India). ${ }^{23}$

Type I error $(a=5 \%)$ 
Precision required on either side of the proportion $(\mathrm{d})=(10 \%$ of $\mathrm{P})$

Formula:

$\mathrm{N}=4 \mathrm{PQ} / \mathrm{d}^{2}$ Where $\mathrm{P}=$ estimated proportion of known diabetics in community (i.e. $7 \%$ )

$\mathrm{Q}=(100-\mathrm{P})$

$d=10 \%$ of P i.e. $20 \%$ of $7=0.7$

$\mathrm{N}=(4 \times 7 \times 93) /(0.7 \times 0.7)=2604 / 0.49=5314$

However, it was decided to survey the total population of 6654 in the study areas to get desired sample size aged 20-80 years.

The subjects were identified by door to door survey based on available records and self-report. They were interviewed using a pre-tested interview schedule with items on socioeconomic and demographic characteristics, history of diabetes, recorded diagnosis in health cards, treatment etc.

Chi-square test was used for qualitative data. Multivariate logistic regression analysis was used to find out socioeconomic and demographic factors associated with T2DM. Odds ratio $(95 \% \mathrm{CI})$ was calculated. ' $\mathrm{p}$ ' $<0.05$ was considered significant.

\section{RESULTS}

Characteristics of study population and prevalence of T2DM is shown in Table 2. Age-group wise, the maximum number of subjects $(23.2 \%)$ in the study population was aged $20-29$ years and least $(5.8 \%)$ were aged $70-80$ years. Age specific prevalence rate was maximum (22.4\%) in the age group 60-69 years and least $(0.2 \%)$ in $20-29$ years. The prevalence showed an increasing trend with increasing age with a slight dip in $70-80$ years $(17.5 \%)$ and it was statistically significant $(\mathrm{p}<0.001)$. The overall prevalence of known T2DM was $8.5 \%(461 / 5444)$ in age group 20-80 years.

Gender wise, the study population consisted of $50.9 \%$ males and $49.1 \%$ females. The prevalence of known T2DM was $9.1 \%$ in males and $7.8 \%$ in females but the difference was not statistically significant $(\mathrm{p}=0.07)$.

Literacy wise, maximum number of study population $(78.7 \%)$ were graduates and above, $45(0.8 \%)$ could only read and write and 52(1.0\%) were illiterates. The prevalence was highest $(25 \%)$ among the study subjects with primary level of literacy status and least $(7.3 \%)$ in graduates and above. The prevalence of known T2DM showed a declining trend with increasing education after primary level and this was statistically significant $(p<0.001)$.

Occupation wise, maximum number of study subjects $(33.3 \%)$ were in private job, followed by household work $(27.5 \%)$ and $8.2 \%$ were unemployed. The prevalence of T2DM was least $(0.7 \%)$ in unemployed and maximum $(19.2 \%)$ in those retired from service and this was statistically significant $(\mathrm{p}<0.001)$.

The prevalence of T2DM was significantly higher $(9.3 \%)$ in joint family than nuclear family $(7.8 \%)(\mathrm{p}=0.04)$. Maximum

\begin{tabular}{|c|c|c|c|}
\hline \multirow[t]{2}{*}{ Variables } & \multicolumn{2}{|c|}{ No (\%) } & \multirow[t]{2}{*}{ 'p' value } \\
\hline & $N=5444$ & Prevalence & \\
\hline Age groups (years) & & & $<0.001$ \\
\hline $20-29$ & $1261(23.2)$ & $3(0.2)$ & \\
\hline $30-39$ & $1074(19.7)$ & $14(1.3)$ & \\
\hline $40-49$ & $1151(21.1)$ & $79(6.9)$ & \\
\hline $50-59$ & $1020(18.7)$ & $170(16.7)$ & \\
\hline $60-69$ & $624(11.5)$ & $140(22.4)$ & \\
\hline $70-80$ & $314(5.8)$ & $55(17.5)$ & \\
\hline Total & $5444(100.0)$ & $461(8.5)$ & \\
\hline Gender & & & 0.07 \\
\hline Male & 2773 (50.9) & $253(9.1)$ & \\
\hline Female & 2671 (49.1) & $208(7.8)$ & \\
\hline Literacy status & & & $<0.001$ \\
\hline Illiterate & $52(1.0)$ & $7(13.5)$ & \\
\hline Read and write & $45(0.8)$ & $11(24.4)$ & \\
\hline Primary & $116(2.1)$ & $29(25.0)$ & \\
\hline Secondary & $293(5.4)$ & $44(15.0)$ & \\
\hline Senior secondary & $652(12.0)$ & $55(8.4)$ & \\
\hline Graduate and above & $4286(78.7)$ & $315(7.3)$ & \\
\hline Occupation & & & $<0.001$ \\
\hline Unemployed & $447(8.2)$ & $3(0.7)$ & \\
\hline Government job & $732(13.4)$ & $60(8.2)$ & \\
\hline Private job & $1813(33.3)$ & $83(4.6)$ & \\
\hline Business & $497(9.1)$ & 54 (10.9) & \\
\hline Household work & $1496(27.5)$ & $173(11.6)$ & \\
\hline Retired & $459(8.4)$ & $88(19.2)$ & \\
\hline Family type & & & 0.04 \\
\hline Nuclear & $3072(56.4)$ & $240(7.8)$ & \\
\hline Joint & $2372(43.6)$ & $221(9.3)$ & \\
\hline Family size & & & 0.94 \\
\hline $1-4$ & $3082(56.6)$ & $259(8.4)$ & \\
\hline $5-8$ & $2175(40.0)$ & $185(8.5)$ & \\
\hline $9-12$ & $187(3.4)$ & $17(9.1)$ & \\
\hline Religion & & & 0.22 \\
\hline Hindu & 4807 (88.3) & $396(8.2)$ & \\
\hline Muslim & $159(2.9)$ & $12(7.5)$ & \\
\hline Sikh & $163(3.0)$ & $16(9.8)$ & \\
\hline Christian & $225(4.1)$ & $25(11.1)$ & \\
\hline Jain & $90(1.7)$ & $12(13.3)$ & \\
\hline Per capita income (INR) & & & 0.09 \\
\hline Up to 10000 & $819(15.0)$ & $58(7.1)$ & \\
\hline $10001-20000$ & 3371 (61.9) & $275(8.2)$ & \\
\hline $20001-30000$ & $1033(19.0)$ & $103(10.0)$ & \\
\hline $30001-40000$ & $191(3.5)$ & $22(11.5)$ & \\
\hline 40001 and above & $30(0.6)$ & $3(10.0)$ & \\
\hline
\end{tabular}


(56.6\%) were having family size of 1 to 4 . The prevalence increased with increasing family size but not statistically significant $(\mathrm{p}=0.94)$.

Religion wise, $88.3 \%$ were Hindus and only $1.7 \%$ were Jains. The prevalence was highest (13.3\%) in Jains and least in Muslims (7.5\%) but the difference was not statistically significant $(\mathrm{p}=0.22)$.

Maximum (61.9\%) of the study population had per capita family income/month of Indian Rupees (INR)10001 to 20000. The prevalence of T2DM was least (7.1\%) in per capita family income per month upto INR 10000, and highest (11.5\%) in INR 30001- 40000 group.

Table 3 shows multivariate logistic regression analysis of various socio-economic and demographic factors associated with prevalence of T2DM in the study population. The associated risk factors were: age 50 years and above (Odds ratio 6.99), male (Odds ratio 1.33), literacy level upto secondary (Odds ratio 1.39), unemployed (Odds ratio 1.45), per capita income INR 20001 and above (Odds ratio 1.39$)$.

\section{DISCUSSION}

The prevalence of known type 2 diabetes mellitus (T2DM) in the present study was $8.5 \%$ among adult population aged 20 to 80 years. This is closely similar to $8.7 \%$ prevalence reported by IDF in South-East Asia and $9 \%$ among adults aged 18 years and above, self reported prevalence of $8.6 \%$ in the United States in 1976-80, 8.3\% in 1999-2000 among adults (20-74 years), $8.4 \%$ among Singapore population aged 18-69 years in 1992. ${ }^{17,18,24-26}$ However, the prevalence is lesser than $12.1 \%$ reported from a nationwide urban survey conducted among adults aged 20 years and above in $2000 .{ }^{27}$ Higher prevalence was also reported from other countries viz. 13.8\% in Qingdao, China in 2006, 12.6\% in Shanghai (2009), 10.3\% in Sri Lanka (2005-06), and 9.8\% in Hong Kong (1995-96). ${ }^{28-31}$

There are variations in the prevalence of diabetes reported from different parts of India. This could be related to the period of study, area (urban or rural), criteria used for diagnosis (self-reported or fasting and post-prandial blood glucose level from capillary or venous sample). Initial large scale nationwide survey conducted by Indian Council of Medical Research (ICMR) during 1972-1976 revealed that the prevalence of diabetes was $2.1 \%$ in urban population, and $5 \%$ in those above 40 years of age. ${ }^{5}$ The second National Urban Diabetes Survey (NUDS) (2001) revealed a high prevalence of diabetes in South India $13.5 \%$ in Chennai, $12.4 \%$ in Bangalore, $16.6 \%$ in Hyderabad) as compared to East India (11.7\% in Kolkata), North India $\left(11.6 \%\right.$ in Delhi), and West India $\left(9.3 \%\right.$ in Mumbai). ${ }^{27}$ Another nation-wide study, the Prevalence of Diabetes in India Study (PODIS) by Sadikot SM et al (2004) reported that standardised prevalence of diabetes in urban Indian

\begin{tabular}{|c|c|c|c|c|c|}
\hline \multirow[t]{2}{*}{ Variables } & \multicolumn{2}{|c|}{ No. $(\%)$} & \multirow{2}{*}{$\begin{array}{l}\text { Odds } \\
\text { ratio }\end{array}$} & \multirow[t]{2}{*}{$95 \% \mathrm{Cl}$} & \multirow[t]{2}{*}{ 'p' value } \\
\hline & $\mathrm{N}=5444$ & Prevalence & & & \\
\hline \multicolumn{6}{|l|}{ Age (years) } \\
\hline Upto 49 & $3486(64.0)$ & $96(2.8)$ & 6.99 & $5.49,8.90$ & $<0.001$ \\
\hline 50 and above & $1958(36.0)$ & $365(18.6)$ & & & \\
\hline \multicolumn{6}{|l|}{ Gender } \\
\hline Male & $2773(50.9)$ & $253(9.1)$ & 1.33 & $1.07,1.65$ & 0.008 \\
\hline Female & $2671(49.1)$ & $208(7.8)$ & & & \\
\hline \multicolumn{6}{|l|}{ Literacy level } \\
\hline Upto secondary & $506(9.3)$ & $91(18.0)$ & 1.39 & $1.05,1.84$ & 0.02 \\
\hline Beyond secondary & $4938(90.7)$ & $370(7.5)$ & & & \\
\hline \multicolumn{6}{|l|}{ Family type } \\
\hline Nuclear & $3072(56.4)$ & $240(7.8)$ & 1.19 & $0.93,1.52$ & 0.16 \\
\hline Joint & $2372(43.6)$ & $221(9.3)$ & & & \\
\hline \multicolumn{6}{|l|}{ Family size } \\
\hline Upto 5 & $4150(76.2)$ & $351(8.5)$ & 1.05 & $0.79,1.40$ & 0.72 \\
\hline 6 and above & $1294(23.8)$ & $110(8.5)$ & & & \\
\hline \multicolumn{6}{|l|}{ Occupation } \\
\hline Employed & $2539(46.6)$ & $142(5.6)$ & 1.45 & $1.15,1.83$ & 0.002 \\
\hline Un-employed & $2905(53.4)$ & $319(11.0)$ & & & \\
\hline \multicolumn{6}{|c|}{ Per capita income per month (INR) } \\
\hline Upto 20000 & $4190(77.0)$ & $333(7.9)$ & 1.39 & $1.10,1.75$ & 0.005 \\
\hline 20001 and above & $1254(23.0)$ & $128(10.2)$ & & & \\
\hline \multicolumn{6}{|l|}{ Religion } \\
\hline Hindu & $4807(88.3)$ & $396(8.2)$ & 1.30 & $0.97,1.74$ & 0.07 \\
\hline Others & $637(11.7)$ & $65(10.2)$ & & & \\
\hline
\end{tabular}


population was $4.3 \% .^{32}$ Subsequent study by Mohan V et al (2008) reported the prevalence of diabetes to be $7.3 \%$ in urban areas of India. ${ }^{33}$ The Chennai Urban Rural Epidemiology Study (CURES) observed a high prevalence of diabetes $(15.5 \%)$. It showed a trend of rising prevalence of diabetes in Chennai by $72.3 \%$ in a span of 14 years. ${ }^{34}$

Studies conducted in Delhi revealed a rising trend of prevalence of diabetes among adults aged 20 plus years from 3.1\% in 1986 (Verma et al) to 4.1\% in 1991 (Ahuja MMS et al), 10.3\% in 2001among 18 plus years (Misra A et al), and 15.0\% among 20-59 years in 2005 (Prabhakaran $\mathrm{D}$ et al). ${ }^{7,14,18,35}$ The differences could be related to increasing prevalence of diabetes over the years and different criteria used for diagnosis of diabetes in the studies. Usually, the report based on known diabetes underestimate the actual prevalence since overt and undiagnosed cases are not taken into consideration. Verma et al used the criteria of known diabetes, whereas Ahuja MMS et al used combination of known and post prandial glucose level, Misra A et al used combination of known and fasting glucose level and Prabhakaran D et al used combination of known, fasting and post prandial glucose levels as the criteria. ${ }^{7,14,18,35}$ The prevalence of $8.5 \%$ reported diabetes in the present study is also an underestimate since the undiagnosed cases were not screened for blood glucose levels.

Higher prevalence of diabetes was reported from different parts of India such as urban areas of Tamilnadu (13.7\%), Maharashtra (10.9\%), Jharkhand (13.5\%) and Chandigarh (14.2\%) (Anjana RM et al, 2001). ${ }^{36}$ Ravikumar P et al (2011) reported age-standardised prevalence of diabetes to be $11.1 \%$ from Chandigarh. ${ }^{20}$ In Manipur, the prevalence was 16.6\% (Shah A et al, 2013). ${ }^{37}$

\section{Age group wise prevalence of diabetes}

The prevalence of known T2DM in the present study showed an increasing trend from $0.2 \%$ in $20-29$ years age group to $22.4 \%$ in 60-69 years age group and slight decline to $17.5 \%$ at $70-80$ years. A similar result was also reported by Qiao Q et al (2003) from their analysis of 11 studies in 4 countries among adults in age group 30-89 years. They reported an increasing prevalence of diabetes with increasing age, reached peak at 70-89 years of age in Chinese and Japanese subjects while in the Indian subjects it peaked at 60-69 years followed by a decline at 70 years of age. The study revealed that Indians had the highest prevalence of diabetes among Asian countries and peak prevalence of prevalence of diabetes reached 10 years younger than Chinese and Japanese population. ${ }^{38}$ The Decode Study Group (2003) analysed data of 13 European cohorts and found that age-specific prevalence of diabetes were less than $10 \%$ in subjects younger than 60 years, and between $10 \%$ to $20 \%$ at $60-79$ years of age. ${ }^{39}$ Secular trend analysis of prevalence of T2DM in Shanghai by Li R et al (2012) showed an increasing trend from $9.7 \%$ in $2002-03$ to $12.6 \%$ in 2009, and the prevalence increased with increasing age. ${ }^{29}$ Chang et al (2000) also observed a significant increase in the prevalence of diabetes with increasing age in Taiwan. ${ }^{40}$ Lu FH et al (1998) from Taiwan observed that prevalence of diabetes and IGT increased from 1.2\% in 20-29 years to $26.9 \%$ in 70 years and above age group. ${ }^{41}$ The possible reason for a dip in the prevalence at $70-80$ years could be related to survivor bias, reflecting deaths at earlier ages due to complications of diabetes. ${ }^{36}$

Multivariate logistic regression analysis in the present study showed that age 50 years and above was associated with higher prevalence of diabetes (Odds ratio: 6.99, 95\% CI 5.49 to 8.90 ). This finding was similar to that reported by Zargar et al (2000) from Kashmir valley which showed that age 50 years above was associated with higher prevalence of diabetes (Odds ratio: 1.87). ${ }^{10}$

\section{Sex-wise prevalence of diabetes}

In the present study, the prevalence of T2DM was higher in males $(9.1 \%)$ than females $(7.8 \%)$ and males were at higher risk of suffering from diabetes than females (Odds ratio: 1.33; 95\% CI 1.07-1.65). This is in conformity with several other studies reported in different countries. Kim et al (2006) reported a higher prevalence among males (8.1\%) than females $(7.5 \%)$ in Korean national health survey (2001) conducted among population aged 20 years and above. ${ }^{42} \mathrm{Li} \mathrm{R}$ et al (2012) also reported that prevalence of T2DM was higher among males than females in Shanghai. ${ }^{29}$ Aeklakorn et al (2011) observed a higher prevalence in males than females in Thai population. ${ }^{43} \mathrm{~A}$ study in Tainan city, Southern Taiwan by Lu FH et al (1998) observed that prevalence of diabetes was higher in males $(10.3 \%)$ than females $(7.9 \%) .{ }^{41}$ In urban Baluchistan, Pakistan, the prevalence of diabetes was $11.1 \%$ in males and $10.6 \%$ in females (Shera et al, 1999). ${ }^{44}$ In Nepal, Ono K et al (2007) reported a higher prevalence of T2DM in males $(11.8 \%)$ than females $(7.9 \%) .{ }^{45}$

In the Indian setting, studies from urban India also reported a higher prevalence in males than females viz. Verma et al (1986) from Delhi (3.8\% in males versus 2.3\% in females), Ramachandran A et al (1992) from Chennai (8.3\% in males versus $7.6 \%$ in females), Shah SK et al (1998) from Guwahati (8.7\% in males versus $7.8 \%$ in females), Ashabai PV et al (1999) from Chennai (8.7\% in males versus $5.7 \%$ in females), Kutty VR et al (2000) from Kerala (16.4\% in males versus $9.2 \%$ in females), Misra A et al (2001) from Delhi (11.2\% in males versus $9.9 \%$ in females), Gupta A et al (2003) from Jaipur (13.2\% in males versus $11.5 \%$ in females), Gupta R et al (2004) from Jaipur $(17.7 \%$ in males versus $14.2 \%$ in females), Mohan V et al (2005) 
from Chennai (18.0\% in males versus $13.4 \%$ in females), and Reddy KS et al (2006) from the national level survey $\left(11.2 \%\right.$ in males versus $6.2 \%$ in females). ${ }^{7,8,12,14,16,17,19,46-48}$ Shah A et al (2013) also observed higher prevalence of diabetes among muslim males $(17.4 \%)$ as compared to $15.2 \%$ in females in Manipur. ${ }^{37}$

Ramachandran A et al (2003) reported that the prevalence of T2DM was not significantly different among males $(13.3 \%)$ and females $(14.3 \%)$ in urban Indians. ${ }^{49}$ Similar observation was also reported by Joseph A et al (2000) from Trivandrum (16.3\% in either gender), from Chennai by Ashabai PV et al (2000) (2.9\% in males versus $3.1 \%$ in females), from the national prevalence by Ramachandran et al (2001) (13.8\% in males versus $14.0 \%$ in females), by Sadikot SM et al (2004) (4.7\% in males versus $4.8 \%$ in females). . $7,32,50,51^{2}$

Some studies showed higher prevalence of diabetes among females than males. Sekikawa A et al (1993) reported the prevalence of diabetes as $14.7 \%$ in males as compared to $18.0 \%$ in females in Japan. ${ }^{52}$ Similarly, Quoc PS et al (1994) also reported that the prevalence of diabetes was higher among females than males in Hanoi, Vietnam. ${ }^{53}$ In Sri Lanka, Katulanda P et al (2008) observed that sex standardized prevalence of diabetes was $9.8 \%$ in males as compared to $10.9 \%$ in females. ${ }^{30}$

\section{Literacy status and diabetes prevalence}

In the present study, the prevalence was highest $(25 \%)$ among the study subjects with primary level of literacy status and least $(7.3 \%)$ in graduates and above. The prevalence of known T2DM showed a declining trend with increasing education after primary level and this was statistically significant $(p<0.001)$. This is consistent with the findings of Ravikumar P et al (2011) who observed a negative association of diabetes with increasing educational status. ${ }^{20}$ However, a study among the police personnel by Kumar $\mathrm{P}$ et al in Bankura, West Bengal did not find any association of educational status (graduate and below graduate) with the prevalence of diabetes. ${ }^{54}$

\section{Income status and diabetes prevalence}

In the present study, multivariate logistic regression analysis showed that per capita income per month in the higher group viz. INR 20001 and above had odds ratio of 1.39 , with $10.2 \%$ prevalence rate of diabetes as compared to $7.9 \%$ in families with per capita income per month less than INR 20000. Similar observation was reported by ICMR-INDIAB study which showed that income status was significantly associated with diabetes (Anjana RM et al, 2011). ${ }^{36} \mathrm{Abu}$ SM et al (1997) also reported that in either urban or rural areas, the highest prevalence of T2DM was observed among the rich, and the lowest prevalence was observed among the poor socioeconomic classes. ${ }^{55}$
Mustafa N et al (2012) observed that prevalence of diabetes was maximum (18\%) in the high income group areas as compared to middle income group area $(11 \%)$ in Jabalpur, Madhya Pradesh. ${ }^{56}$ Kumar SS et al (1998) also observed that increasing socioeconomic status was associated with higher prevalence of T2DM in Assam with an odds ratio of $1.55 .{ }^{57}$ Rao CR et al (2010) reported a high prevalence of diabetes $(32 \%)$ in the high socio-economic status with an odds ratio of 3.29 from Karnakata. ${ }^{58}$

Agarwal P et al (2013) observed that prevalence of diabetes was highest in the middle socio-economic status $(25.7 \%)$ as compared to low $(10.0 \%)$ and high socio-economic status group (10.0\%) in Ahmedabad city among subjects aged 30 years and more. ${ }^{59}$

\section{Occupation and diabetes prevalence}

In the present study, prevalence of diabetes was maximum $(19.2 \%)$ in those retired from service, followed by $11.6 \%$ in those with household work and 10.9\% among adults in business. Multivariate logistic regression analysis showed that unemployed were more at risk of suffering from diabetes than employed (Odds ratio: 1.45; 95\%CI 1.151.83). The findings are different from the study conducted by Rao CR (2010) who did multivariate logistic regression analysis and identified that skilled or professional job were considered to have significant co-relationship with diabetes. ${ }^{58}$ Other studies also reported similar finding (Misra A et al, 2001; Kutty VR et al, 2000, Gupta A et al, 2003)..$^{14,47,48}$ The high prevalence among the retired persons in the present study could be related to the older age and other factors such as physical inactivity among the retired persons.

\section{Limitation of the study}

In the present study, prevalence was based on self-report by the patients and thus, the expected prevalence might be higher than that reported in the study.

\section{CONCLUSION}

The prevalence of known Type $2 \mathrm{DM}$ in 20-80 years was $8.5 \%$, highest $(22.4 \%)$ in $60-69$ years, higher in males $(9.1 \%)$ than females $(7.8 \%)$, highest in those educated upto primary level $(25 \%)$, more in those with per capita income of INR.20001 and above (10.2\%), maximum in retired from service $(19.2 \%)$. The prevalence of T2DM showed an increasing trend with increasing age.

\section{REFERENCES}

1. American Diabetes Association.Diagnosis and Classification of Diabetes Mellitus.Diabetes Care 2010; 33Suppl 1: S62-S69.

2. Sicree R, Shaw J and Zimmet P. The Global Burden: Diabetes 
and Impaired Glucose Tolerance. [online] 2009 [cited 2015 November 24]. Available from: URL: http://www.idf.org/ sites/default/files/The_Global_Burden.pdf.

3. International Diabetes Federation. IDF Diabetes Atlas, $6^{\text {th }}$ edition [online] 2014 [cited 2015 June 6]. Available from: URL:http:// www.idf.org/sites/default/files/Atlas-poster-2014_EN.pdf.

4. Wild S, Roglic G, Green A, Sicree R and King H. Global prevalence of diabetes: Estimates for the year 2000 and projections for 2030. Diabetes Care 2004; 27: 1047-1053.

5. Ahuja MMS. Epidemiological studies on diabetes mellitus in India. In: Ahuja MMS, eds. Epidemiology of diabetes in developing countries. New Delhi: Interprint, 1979, pp 29-38.

6. Ramachandran A, Jali MV, Mohan V, Snehalatha C and Viswanathan M. High prevalence of diabetes in an urban population in South India. Br Med J 1988; 297: 587-590.

7. Varma NPS, Mehta SP, Madhu SV, Mather HM and Keen H. Prevalence of known diabetes mellitus in an urban Indian environment: the Darya Ganji diabetes survey. Br Med J 1986; 293: 423.

8. Ramachandran A, Snehalatha C, Dharmaraj D and Viswanathan M. Prevalence of glucose intolerance in Asian Indians. Urban-rural difference and significance of upper body adiposity.Diabetes Care1992; 15: 1348-1355.

9. Ramachandran A, Snehalatha C, Latha E, Vijay V and Viswanathan M. Rising prevalence of NIDDM in urban population of India. Diabetologia 1997; 40:232-237.

10. Zargar AH, Khan AK, Masoodi SR, Laway BA, Wani AI, Bashir MI, et al. Prevalence of type 2 diabetes mellitus and impaired glucose tolerance in the Kashmir Valley of the Indian subcontinent. Diabetes Res Clin Pract 2000; 47: 135-136.

11. Raman KV, Joseph $A$ and Soman CR. High prevalence of type 2 diabetes in an urban settlement in Kerala. India.Ethn Health 1999; 4:231-239.

12. Shah SK, Saikia M, Barman NN, Snehalatha C and Ramachandran A. High prevalence of type 2 diabetes in urban population in north-eastern India. Int J Diab Dev Countries 1999; 19:144-147.

13. Iyer SR, lyer RR, Upasani SV and Baitule MN. Diabetes mellitus in Dombivli-an urban population study. J Assoc Physicians India 2001; 49:713-716.

14. Misra A, Pandey RM, Devi JR, Sharma R, Vikram NK and Khanna N. High prevalence of diabetes, obesity and dyslipidaemia in urban slum population in northern India. Int $\mathrm{J}$ Obes 2001; 25:1722-1729.

15. Mohan V, Shanthirani CS and Deepa R. Glucose intolerance (diabetes and IGT) in a selected South Indian population with special reference to family history, obesity and lifestyle factors - the Chennai Urban Population Study. J Assoc Physicians India 2003; 51:771-777.

16. Gupta R, Sarna M, Thanvi J, Sharma V, Rastogi P, Kaul V, et al. High prevalence of multiple coronary risk factors in Punjabi Bhatia community. Ind Heart J 2004; 56:646-652.

17. Mohan V, Deepa R, Somannavar S and Datta M. A simplified Indian Diabetes Risk Score for screening for undiagnosed diabetes subjects. J Assoc Physicians Ind 2005; 53:759-763.

18. Prabhakaran D, Shah P, Chaturvedi V, Ramakrishnan L, Manhapra A and Reddy KS. Cardiovascular risk factor prevalence among men in a large industry of northern India. Natl Med J India 2005; 18:59-65.

19. Reddy KS, Prabhakaran D, Chaturvedi V, Jeemon $P$, Thankappan KR, Ramakrishnan L, et al. Methods for establishing a surveillance system for cardiovascular diseases in Indian industrial populations. Bull WHO 2006; 84:461-469.

20. Ravikumar P, Bhansali A, Ravikiran M, Bhansali S, Walia
$\mathrm{R}$ and Shanmugasundar G. Prevalence and risk factors of diabetes in a community-based study in North India: the Chandigarh Urban Diabetes Study (CUDS). Diabetes Metab 2011; 37(3):216-221.

21. Mustafa $\mathrm{N}$ and Kushwaha $\mathrm{S}$. Prevalence of Diabetes mellitus in the urban population of Jabalpur district, India. Current Biotica 2012; 6(3): 364-369.

22. Gujral UP, Narayan KM, Pradeepa RG, Deepa M, Ali MK, Anjana RM, et al. Comparing Type 2 Diabetes, Prediabetes, and Their Associated Risk Factors in Asian Indians in India and in the U.S.: The CARRS and MASALA Studies. Diabetes Care 2015; 38(7):1312-1318.

23. Shah $B$ and Mathur P. Risk factor surveillance for non-communicable diseases (NCDs): the multi-site ICMR-WHO collaborative initiative. [online] 2005 [cited 2015 August 25]. Available from: URL: http://www.globalforumhealth.org/filesupld/ forum9/CD\%20Forum\%209/papers/Shah\%20B.pdf

24. International Diabetes Federation. Regional overviews. [online] 2014 [cited 2015 June 6]. Available from: URL: http://www.idf. org/sites/default/files/EN_6E_Ch3_Regional_Overviews.pdf.

25. Gregg EW, Cadwell BL, Cheng YJ, Cowie CC, Williams DE, Geiss $\mathrm{L}$, et al. Trends in the prevalence and ratio of diagnosed to undiagnosed diabetes according to obesity levels in the US. Diabetes Care 2004; 27: 2806-2812.

26. Tan CE, Emmanuel SC, Tan BY and Jacob E. Prevalence of diabetes and ethnic differences in cardiovascular risk factors. The 1992 Singapore National Health Survey. Diabetes Care 1999; 22: 241-247.

27. Ramachandran A, Snehalatha C, Kapur A, Vijay V, Mohan V, Das AK, et al. High prevalence of diabetes and impaired glucose tolerance in India: National Urban Diabetes Survey. Diabetologia 2001; 44: 1094-1101.

28. Gao WG, Dong YH, Pang ZC, Nan HR, Zhang L, Wang SJ, et al. Increasing trend in the prevalence of Type 2 diabetes and pre-diabetes in the Chinese rural and urban population in Qingdao, China. Diabet Med 2009;26(12):1220-1227.

29. Li R, Lu W, Jiang QW, Li YY, Zhao GM, Shi L, et al. Increasing prevalence of type 2 diabetes in Chinese adults in Shanghai. Diabetes Care 2012;35(5):1028-1030.

30. Katulanda P, Constantine GR, Mahesh JG, Sheriff R, Seneviratne RD, Wijeratne $S$, et al. Prevalence and projections of diabetes and pre-diabetes in adults in Sri Lanka--Sri Lanka Diabetes, Cardiovascular Study (SLDCS). Diabet Med 2008;25(9):1062-1069.

31. Janus ED, Watt NM, Lam KS, Cockram CS, Siu ST, Liu LJ, et al. The prevalence of diabetes, association with cardiovascular risk factors and implications of diagnostic criteria (ADA 1997 and WHO 1998) in a 1996 community-based population study in Hong Kong Chinese. Hong Kong Cardiovascular Risk Factor Steering Committee. American Diabetes Association. Diabet Med 2000; 17(10):741-745.

32. Sadikot SM, Nigam A, Das S, Bajaj $S$, Zargar $A H$, Prasannakumar KM, et al. Comparing the ADA 1997 and the WHO 1999 criteria: Prevalence of Diabetes in India Study. Diabetes Res Clin Pract 2004; 66: 309-315.

33. Mohan V, Mathur P, Deepa R, Deepa M, Shukla DK, Menon GR, et al. Urban rural differences in prevalence of self-reported diabetes in India-theWHO-ICMR Indian NCD risk factor surveillance. Diabetes Res Clin Pract 2008; 80:159-168.

34. Deepa M, Pradeepa R, Rema M, Mohan A, Deepa R, Shanthirani $S$, et al. The Chennai Urban Rural Epidemiology Study (CURES)--study design and methodology (urban component) (CURES-I). J Assoc Physicians India 2003; 51:863-870.

35. Ahuja MMS. Recent contributions to the epidemiology of 
diabetes mellitus in India. Int J Diab Developing Countries 1991; 11:5-9.

36. Anjana RM, Pradeepa R, Deepa M, Datta M, Sudha V, Unnikrishnan R, et al. Prevalence of diabetes and prediabetes (impaired fasting glucose and/or impaired glucose tolerance) in urban and rural India: phase I results of the Indian Council of Medical Research-India DIABetes (ICMR-INDIAB) study. Diabetologia 2011; 54(12):3022-3027.

37. Shah A and Afzal M. Prevalence of diabetes and hypertension and association with various risk factors among different Muslim populations of Manipur, India. J Diabetes Metab Disord 2013; 12(1):52.

38. Qiao Q, Hu G, Tuomilehto J, Nakagami T, Balkau B, Borch-Johnsen K, et al. Age and Sex-Specific Prevalence of Diabetes and Impaired Glucose Regulation in 11 Asian Cohorts. Diabetes Care 2003; 26(6):1770-1780.

39. The Decode Study Group. Age- and Sex-Specific Prevalences of Diabetes and Impaired Glucose Regulation in 13 European Cohorts. Diabetes Care 2003; 26:61-69.

40. Chang C-J, Lu F-H, Yang Y-C, Wu J-H, Wu T-J, Chen M-S, et al. Epidemiologic study of type 2 diabetes in Taiwan. Diabetes Res Clin Pract 2000; 50 Suppl 2: 49-59.

41. Lu F-H, Yang Y-C, Wu J-S, Wu C-H and Chang C-J. A population-based study of the prevalence and associated factors of diabetes mellitus in southern Taiwan. Diabet Med 1998; 15:564-572.

42. Kim SM, Lee JS, Lee J, Na JK, Han JH, Yoon DK,et al. Prevalence of diabetes and impaired fasting glucose in Korea: Korean national health and nutrition survey 2001. Diabetes Care 2006; 29:226-231.

43. Aeklakorn $\mathrm{W}$, Chariyalertsak $\mathrm{S}$, Kessomboon $\mathrm{P}$, Sangthong $\mathrm{R}$, Inthawong R, Putwatana P, et al. Prevalence and management of diabetes and metabolic risk factors in Thai adults. Diabetes Care 2011; 34:1980-1985.

44. Shera AS, Rafique G, Khawaja IA, Baqai S, and King H. Pakistan National Diabetes Survey: prevalence of glucose intolerance and associated factors in Baluchistan province. Diabetes Res Clin Pract 1999; 44(1):49-58.

45. Ono K, Limbu YR, Rai SK, Kurokawa M, Yanagida J and Rai G. The prevalence of type 2 diabetes mellitus and impaired fasting glucose in semi-urban population of Nepal. Nepal Med Coll J 2007; 9(3):154-156.

46. Ashabai PV, Krishnaswami CV and Chellamariappan M. Prevalence and incidence of type-2 diabetes and impaired glucose tolerance in a selected Indian urban population. J Assoc Physicians India 1999; 47:1060-1064.
47. Kutty VR, Soman CR, Joseph A, Pisharody R and Vijayakumar K. Type 2 diabetes in southern Kerala: variation in prevalence among geographic divisions within a region. Natl Med J India 2000; 13:287-292.

48. Gupta A, Gupta R, Sarna M, Rastogi S, Gupta VP AND Kothari K. Prevalence of diabetes, impaired fasting glucose and insulin resistance syndrome in an urban Indian population. Diab Res Clin Pract 2003; 61:69-76.

49. Ramachandran A, Snehalatha C, Satyavani K and Vijay V. Impaired fasting glucose and impaired glucose tolerance in urban population in India. Diabet Med 2003; 20(3):220-224.

50. Joseph A, Kutty VR and Soman CR. High risk for coronary heart disease in Thiruvananthapuram city: a study of serum lipids and other risk factors. Indian Heart J 2000; 52:29-35.

51. Ashabai PV, Murthy BN, Chellamariappan M, Gupte MD and Krishnaswami CV. Prevalence of known diabetes in Chennai City. J Assoc Physicians India 2000; 49:974-981.

52. Sekikawa A, Tominaga M, Takahashi K, Eguchi H, Igarashi M, Ohnuma $\mathrm{H}$, et al. Prevalence of diabetes and impaired glucose tolerance in Funagata area, Japan. Diabetes Care 1993; 16(4):570-574.

53. Quoc PS, Charles MA, Cuong NH, Lieu LH, Tuan NA, AND Thomas M.Blood glucose distribution and prevalence of diabetes in Hanoi (Vietnam). Am J Epiodemiol 1994; 139(7):713-722.

54. Kumar P, Mallik D, Mukhopadhyay DK, Sinhababu A, Mahapatra BS and Chakrabarti P. Prevalence of diabetes mellitus, impaired fasting glucose, impaired glucose tolerance, and its correlates among police personnel in Bankura District of West Bengal. Indian J Public Health 2013; 57(1):24-28.

55. Abu SM, Ali L, Hussain MZ, Rumi MA, Banu A and Azad KAK. Effect of socioeconomic risk factors on the difference in prevalence of diabetes between rural and urban populations in Bangladesh. Diabetes Care 1997;20(4):551-555.

56. Mustafa $\mathrm{N}$ and Kushwaha S. Prevalence of Diabetes mellitus in the urban population of Jabalpur district, India. Current Biotica 2012; 6(3):364-369.

57. Kumar SS, Saikia M, Snehalatha C and Ramachandran A. High prevalence of type2 diabetes in urban population in north eastern India. Int J Diab Dev Countries 1998; 18:97-100.

58. Rao CR, Kamath VG, Shetty A and Kamath A. A study on the prevalence of type 2 diabetes in coastal Karnataka. Int $\mathrm{J}$ Diabetes Dev Ctries 2010; 30(2):80-85.

59. Agarwal P, Jadeja JM and Naik SS. Prevalence of diabetes mellitus type 2 in the general population of Ahmedabad city. International Journal of Basic and Applied Physiology 2013; 2(1):197-202. 